\title{
Der Entscheid über Migration als Verfügungsrecht
}

Eine Anwendung der Ökonomischen Analyse des Rechts auf das Migrationsrecht am Beispiel der Schweiz

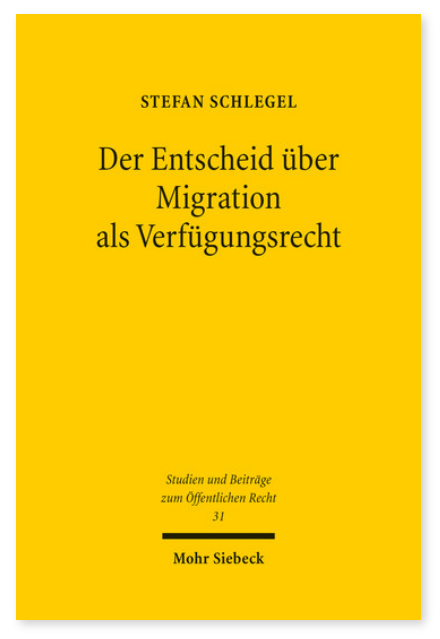

2017. XXI, 375 Seiten. StudÖR 31

ISBN 978-3-16-154888-8

DOI 10.1628/978-3-16-154888-8

eBook PDF 94,00€

ISBN 978-3-16-154872-7

fadengeheftete Broschur 94,00€
Stefan Schlegel wendet die Theorie der Verfügungsrechte auf das Migrationsrecht an und illustriert deren Erkenntniswert für das Migrationsrecht am konkreten Beispiel des Schweizer Rechts. Nach der Theorie der Verfügungsrechte besteht die Aufgabe der Rechtsordnung in erster Linie darin, Verfügungsrechte über Güter in der Gesellschaft zuzuordnen und festzulegen, nach welcher Transaktionsregel das Verfügungsrecht übertragen werden kann. Die Kontrolle über die Migration einer bestimmten Person an einen bestimmten Ort ist die Kontrolle über ein Gut und damit ein Verfügungsrecht. Die Rechtsordnung muss es zuweisen und Transaktionsregeln festlegen.

Wählt das geltende Migrationsrecht die Kombination aus Allokation des Verfügungsrechtes und Transaktionsregeln so, dass das Verfügungsrecht zu seinem größtmöglichen Wert entwickelt werden kann? Der Autor verneint dies und sucht auf systematische Weise nach Kombinationen aus Allokationsentscheid und Transaktionsregel, welche eine Ausschöpfung des potentiellen Wertes des Verfügungsrechtes über Migration besser gewährleisten.

Stefan Schlegel Geboren 1983; Studium der Rechtswissenschaft an der Universität Zürich; Assistenz- und Doktorat an der Universität Bern; Forschungsaufenthalt an der Universität Toronto; zurzeit wissenschaftlicher Mitarbeiter am Max Planck Institut zur Erforschung multireligiöser und multiethnischer Gesellschaften, Göttingen.
Jetzt bestellen:

https://mohrsiebeck.com/buch/der-entscheid-ueber-migration-als-verfuegungsrecht-9783161548888?no_cache=1 order@mohrsiebeck.com

Telefon: +49 (0)7071-923-17

Telefax: +49(0)7071-51104 